\title{
Evaluation of retinal nerve fiber layer and choroidal thickness with spectral domain optical coherence tomography in children with sickle cell anemia
}

\author{
Kamil Yılmaz ${ }^{1 \oplus}$, Hasan Öncül ${ }^{2 \oplus}$, Hülya Uzel ${ }^{3 \oplus}$, Kahraman Öncel $^{4 \oplus}$, \\ E. Deniz Yilmaz ${ }^{50}$, Murat Söker ${ }^{30}$ \\ Departments of ${ }^{1}$ Pediatrics Infectious Diseases, ${ }^{3}$ Pediatric Hematology and ${ }^{5}$ Pathology, Dicle University Faculty of Medicine, \\ Diyarbakır; Departments of ${ }^{2}$ Ophthalmology and ${ }^{4}$ Pediatric Hematology, University of Health Sciences Gazi Yaşargil Education \\ Research Hospital, Diyarbakır, Turkey.
}

\begin{abstract}
Background. The aim of this study is to examine the thickness of choroidal, macular and peripapillary retinal nerve fiber layer by spectral-domain optical coherence tomography (SD-OCT) in pediatric patients with sickle cell anemia (SCA) without retinopathy.

Methods. A total of 75 children (30 SCA patients (Group 1) and 45 healthy individuals (Group 2) were included in the study. Macular (central, superior, inferior, nasal, temporal), choroidal (subfoveal, at nasal distances from the central fovea of $1000 \mu \mathrm{m}$ [N1], $2000 \mu \mathrm{m}$ [N2], $3000 \mu \mathrm{m}$ [N3], at temporal distances from the central fovea of $1000 \mu \mathrm{m}$ [T1], $2000 \mu \mathrm{m}$ [T2], $3000 \mu \mathrm{m}$ [T3]) and RNFL (average, temporal, superotemporal, inferotemporal, nasal, inferonasal and superonasal) measurements were performed by SD-OCT. These parameters were compared with healthy children with similar demographic characteristics.
\end{abstract}

Results. The mean age was $14.11 \pm 3.86$ (11-18) in sickle cell anemia patients and $13.15 \pm 2.69$ (10-18) in the healthy control group. Of the patients, 56.6\% $(n=17)$ of Group 1 and $44.4 \%(n=20)$ of Group 2 were male. Choroidal measurements made in the subfoveal, N1, N2, N3, T1, T2 and T3 quadrants showed that the choroid was thinner in 6 quadrants in SCA patients compared to the healthy group $(p=0.003, p=0.039, p=0.035, p=0.595$, $\mathrm{p}=0.006, \mathrm{p}=0.005, \mathrm{p}=0.047$, respectively). In RNFL measurements, there was significant thinning in the temporal, inferotemporal, and nasal quadrants of SCA patients compared to the healthy group. Changes in other quadrants were not significant.

Conclusions. SD-OCT is a useful imaging method in the diagnosis and screening in patients with SCA without retinopathy. Early diagnosis of retinopathy during subclinical disease will prevent visual loss in these patients.

Key words: choroidal thickness, retinal nerve fiber layer, sickle cell anemia, spectral-domain optical coherence tomography

Sickle cell anemia (SCA) is one of the most common hemoglobinopathies around the world. $\mathrm{Hb} \mathrm{S}$, abnormal hemoglobin, is formed as a result of glutamic acid replacing valine at position 6 of the globin chain. In this disease showing autosomal recessive inheritance, the term SCA is used for patients with homozygous

$\bowtie$ Murat Söker

sokerm@hotmail.com

Received 18th August 2020, revised 28th November 2020, 23rd December 2020, accepted 29th January 2021.
$\mathrm{Hb} \mathrm{S}$, while the coinheritance of $\mathrm{Hb} \mathrm{S}$ with other hemoglobin variants is called the sickling syndromes. The frequency of the SCA trait is $0.3-0.6 \%$ throughout Turkey, while this rate reaches $3-44 \%$ in some parts of the Cukurova region. ${ }^{1}$

Pathologies that occurin SCA target many organs and tissues. The pathogenesis of the disease includes anemia caused by chronic hemolysis, vascular damage, and organ and tissue ischemia due to a defect in blood flow. ${ }^{2}$ The ocular manifestations of the disease may be observed 
in a wide spectrum ranging from the orbit to the retina. While anterior segment findings are frequently seen as comma-shaped vessels in the conjunctiva, cataract and iris atrophy may also develop in these patients. ${ }^{3}$ Retinal vascular lesions observed in the posterior segment often occur secondary to neovascularization and ischemia in the peripheral retina. Patients are classified as proliferative or nonproliferative according to the presence of posterior segment neovascularization. ${ }^{4}$ Visual loss usually occurs in the proliferative stage, in which vitreous hemorrhage, epiretinal membrane, and retinal detachment are observed. ${ }^{5}$ However, in patients not progressing to the proliferative stage, decreased retinal sensitivity may be observed in addition to subclinical sectoral thinning in the peripapillary retinal nerve fiber layer (RNFL) and thinning in the fovea by spectraldomain optical coherence tomography (SDOCT). ${ }^{6,7}$ Besides, these patients may experience decreased vision due to pathologies such as abnormal perfusion-related macular infarction and ischemic optic neuropathy. ${ }^{8}$

Ocular structures such as RNFL and choroid with intense vascularization are expected to be affected in SCA, which is a disease presenting with hypoxia due to vascular occlusion and chronic anemia. Possible disorders in these structures may result in decreased visual function. The aim of this study was to evaluate RNFL, macular, and choroidal thickness measurements by SD-OCT in patients with SCA and compare these data with a demographically similar healthy group.

\section{Material and Methods}

This observational prospective clinical study was conducted between July 2017 and December 2019 after being approved by the ethics committee of Dicle University Faculty of Medicine (23.06.2017- report number:24). The study was conducted in accordance with the Helsinki Declaration, and a written informed consent form was obtained from all participants.
A total of 75 children (30 SCA patients (Group 1), 45 healthy individuals (Group 2) were included in the study, and both eyes of the participants were evaluated. The mean values of both eyes were recorded in the database. Group 1 consisted of children aged 11-18 years who were diagnosed with homozygous $\mathrm{Hb} \mathrm{SS}$ (sickle cell anemia), whose parents were $\mathrm{Hb} \mathrm{S}$ carriers, with a $\mathrm{Hb}$ S level $>40 \%$ and no $\mathrm{Hb} \mathrm{A}$ according to the hemoglobin electrophoresis results. Group 2 consisted of healthy children aged 10-18 years without any chronic diseases. In Group 1, the ferritin level, mean number of vaso-occlusive painful crises per year, and blood transfusion requirement were determined by scanning patient files. Disease duration was determined as the period between diagnosis and study time. Exclusion criteria included the best-corrected visual acuity below 20/20, refractive error more than $\pm 1 \mathrm{D}$, presence of corneal pathology, presence of retinal/choroidal pathology other than SCA, intraocular pressure more than $21 \mathrm{mmHg}$, glaucomatous optic disc changes, axial length more than $24 \mathrm{~mm}$, previous ocular trauma or surgery. Those with chronic additional systemic diseases, those unable to adapt to ophthalmologic examination, and those under 10 years of age were excluded from the study.

All participants underwent detailed ophthalmologic examination including refraction, cycloplegic refraction, best-corrected visual acuity, biomicroscopic examination, dilated fundus examination (via 90 D lens), intraocular pressure measurement (Reichert R7 non-contact tonometer, Reichert, USA), axial length measurement (AL-Scan Optical Biometer; Nidek, Gamagori, Japan) and central corneal thickness measurement (Pentacam ${ }^{\circledR}$ HR, OCULUS, Wetzlar, Germany) by the same clinician. SD-OCT (Heidelberg Engineering, Heidelberg, Germany) measurements were performed by the same clinician between 10.0011.00 a.m. so that the measurements were not affected by diurnal variations.

Macular thickness was measured automatically in the central, superior, inferior, temporal, 
and nasal quadrants using the readymade package program of the instrument. RNFL measurements were performed automatically in 7 quadrants including the average, superonasal, superotemporal, nasal, inferonasal, inferotemporal, and temporal quadrants. Choroidal thickness was measured manually using the enhanced depth imaging OCT (EDI-OCT) mode of the instrument. The interface of the Bruch membrane was considered the anterior edge of the choroid, and the sclerochoroidal interface was considered the posterior border of the choroid. Choroidal thickness was measured in 7 different regions including the subfoveal region, nasal distances from the central fovea of $1000 \mu \mathrm{m}$ [N1], $2000 \mu \mathrm{m}$ [N2], $3000 \mu \mathrm{m}$ [N3], temporal distances from the central fovea of $1000 \mu \mathrm{m}$ [T1], $2000 \mu \mathrm{m}$ [T2], $3000 \mu \mathrm{m}$ [T3].

\section{Statistical analysis}

All statistical analyses were performed using Statistical Package for Social Sciences (SPSS), Version 24.0 for Windows. The variables were investigated using visual (histograms, probability plots) and analytical methods (Kolmogorov-Simonov test) whether or not they were normally distributed. Dats are presented as mean \pm standard error. The chi-square test was used to compare these proportions in different groups. Comparisons between groups were performed using the Student's t-test. P values lower than 0.05 was considered statistically significant.

\section{Results}

A total of 75 children, 30 SCA patients (Group 1 ), and 45 healthy individuals (Group 2), were included in the study. The mean age was $14.11 \pm 3.86$ (11-18) in sickle cell anemia patients and $13.15 \pm 2.69(10-18)$ in the healthy control group. Of the patients, $56.6 \%(n=17)$ of Group 1 and $44.4 \%(n=20)$ of Group 2 were male. No difference was found between the groups in terms of age and gender distribution $(p=0.053$, $\mathrm{p}=0.550$, respectively). The demographic and ocular characteristics of the participants are shown in Table I.

The mean $\mathrm{Hb} \mathrm{S}$ level was $59.99 \pm 8.44 \mathrm{~g} / \mathrm{dL}$, and the mean ferritin level was $470.3 \pm 79.4$ $\mu \mathrm{g} / \mathrm{L}$ in Group 1. Other clinical and laboratory characteristics of the patients with SCA are shown in Table II.

7 different choroidal thickness measurements made in the subfoveal, nasal and temporal quadrants (subfoveal, N1, N2, N3, T1, T2, T3) showed that the choroid was thinner in 6 quadrants in SCA patients compared to the healthy group $(\mathrm{p}=0.003, \mathrm{p}=0.039, \mathrm{p}=0.035, \mathrm{p}=$ $0.595, p=0.006, p=0.005, p=0.047$, respectively) (Table III). There was no statistical difference between the two groups in terms of macular thickness measurements (Table IV). RNFL analysis was performed in 7 quadrants (average, temporal, superotemporal, inferotemporal, nasal, inferonasal and superonasal). There was significant thinning in the temporal,

Table I. Baseline characteristics of sickle cell anemia patients and healthy controls.

\begin{tabular}{lccc}
\hline Parameters & Sickle cell anemia $(\mathrm{n}=30)$ & Healthy controls $(\mathrm{n}=45)$ & $\mathrm{p}$ \\
\hline $\begin{array}{l}\text { Age (years) } \\
\text { (Mean } \pm \text { SD } /(\text { Median age }))\end{array}$ & $14.11 \pm 3.86(15.50)$ & $13.15 \pm 2.69(13.00)$ & 0.053 \\
$\begin{array}{l}\text { Gender }(\mathrm{M} / \mathrm{F}) \\
\begin{array}{l}\text { Ocular blood pressure } \\
(\text { Mean } \pm \text { SD) }\end{array}\end{array}$ & $17 / 13$ & $20 / 25$ & 0.550 \\
$\begin{array}{l}\text { Central corneal thickness }(\mu \mathrm{m}) \\
(\text { Mean } \pm \text { SD) }\end{array}$ & $12.94 \pm 0.82$ & $12.88 \pm 1.34$ & 0.876 \\
$\begin{array}{l}\text { Axial length }(\mathrm{mm}) \\
\text { (Mean } \pm \text { SD) }\end{array}$ & $522.13 \pm 9.85$ & $518.57 \pm 8.65$ & 0.187 \\
\hline
\end{tabular}

M: male, F: female, SD: standard deviation 
Table II. Clinical and laboratory characteristics of patients with sickle cell anemia.

\begin{tabular}{|c|c|}
\hline Parameters & Mean $\pm S D$ \\
\hline $\mathrm{HbS}(\mathrm{g} / \mathrm{dL})$ & $59.99 \pm 8.44$ \\
\hline Serum ferritin $(\mu \mathrm{g} / \mathrm{L})$ & $470.33 \pm 79.4$ \\
\hline Number of transfusions ${ }^{a}$ & $1.44 \pm 0.38$ \\
\hline Number of crises ${ }^{\mathrm{b}}$ & $2.72 \pm 1.52$ \\
\hline Disease duration (year) $^{c}$ & $11.27 \pm 4.88$ \\
\hline
\end{tabular}

${ }^{a}$ : the number of blood transfusions per year

${ }^{b}$ : the number of crises per year

c: time from being diagnosed with sickle cell anemia to study. inferotemporal and nasal quadrants of SCA patients compared to the healthy group. Changes in other quadrants were not significant $(\mathrm{p}=0.665, \mathrm{p}=0.043, \mathrm{p}=0.230, \mathrm{p}=0.018, \mathrm{p}=0.013$, $\mathrm{p}=0.706, \mathrm{p}=0.631$, respectively) (Table V).

The number of annual crises was found to be positively correlated with the ferritin level and frequency of transfusion $(\mathrm{p}=0.017, \mathrm{p}=0.006$, respectively). However, no correlation was found between the number of annual crises and choroidal thickness, macular thickness, and RNFL measurements.

Table III. Choroidal thickness values in sickle cell anemia patients and healthy controls.

\begin{tabular}{lccc}
\hline Choroidal thickness $(\mu \mathrm{m})$ & $\begin{array}{c}\text { Sickle cell anemia }(\mathrm{n}: 30) \\
\text { mean } \pm \text { SD }\end{array}$ & $\begin{array}{c}\text { Healthy controls }(\mathrm{n}: 45) \\
\text { mean } \pm \text { SD }\end{array}$ & $\mathrm{p}$ \\
\hline Subfoveal & $297.11 \pm 40.77$ & $337.59 \pm 44.41$ & 0.003 \\
Nasal 1000 & $253.52 \pm 50.10$ & $285.40 \pm 48.63$ & 0.039 \\
Nasal 2000 & $202.72 \pm 48.48$ & $236.61 \pm 52.95$ & 0.035 \\
Nasal 3000 & $155.66 \pm 38.37$ & $162.33 \pm 42.51$ & 0.595 \\
Temporal 1000 & $274.69 \pm 31.26$ & $308.51 \pm 42.10$ & 0.006 \\
Temporal 2000 & $244.66 \pm 38.42$ & $278.33 \pm 37.23$ & 0.005 \\
Temporal 3000 & $213.97 \pm 27.55$ & $238.22 \pm 51.48$ & 0.047 \\
\hline
\end{tabular}

SD: standard deviation

Table IV. Macular thickness values in sickle cell anemia patients and healthy controls.

\begin{tabular}{lccc}
\hline Macular thickness $(\mu \mathrm{m})$ & $\begin{array}{c}\text { Sickle cell anemia (n:30) } \\
\text { mean } \pm \text { SD }\end{array}$ & $\begin{array}{c}\text { Healthy controls }(\mathrm{n}: 45) \\
\text { mean } \pm \text { SD }\end{array}$ & $\mathrm{p}$ \\
\hline Central & $258.55 \pm 14.84$ & $259.59 \pm 19.39$ & 0.849 \\
Superior quadrant & $345.05 \pm 10.44$ & $344.38 \pm 9.26$ & 0.823 \\
Inferior quadrant & $345.50 \pm 10.19$ & $340.07 \pm 11.42$ & 0.111 \\
Temporal quadrant & $330.30 \pm 11.27$ & $327.66 \pm 10.52$ & 0.428 \\
Nasal quadrant & $344.41 \pm 9.05$ & $341.59 \pm 12.18$ & 0.406
\end{tabular}

SD: standard deviation

Table V. RNFL thickness values in sickle cell anemia patients and healthy controls.

\begin{tabular}{lccc}
\hline RNFL thickness $(\mu \mathrm{m})$ & $\begin{array}{c}\text { Sickle cell anemia }(\mathrm{n}: 30) \\
\text { mean } \pm \text { SD }\end{array}$ & $\begin{array}{c}\text { Healthy controls }(\mathrm{n}: 45) \\
\text { mean } \pm \text { SD }\end{array}$ & $\mathrm{p}$ \\
\hline Average & $106.05 \pm 10.49$ & $104.79 \pm 8.78$ & 0.665 \\
Temporal quadrant & $75.05 \pm 8.30$ & $69.72 \pm 8.44$ & 0.043 \\
Superotemporal quadrant & $145.38 \pm 18.59$ & $139.27 \pm 14.97$ & 0.230 \\
Inferotemporal quadrant & $155.50 \pm 23.36$ & $139.59 \pm 19.70$ & 0.018 \\
Nasal quadrant & $73.22 \pm 16.57$ & $84.92 \pm 13.72$ & 0.013 \\
Inferonasal quadrant & $132.61 \pm 28.93$ & $129.61 \pm 23.83$ & 0.706 \\
Superonasal quadrant & $124.44 \pm 25.27$ & $121.12 \pm 20.56$ & 0.631 \\
\hline
\end{tabular}

RNFL: retinal nerve fiber layer, SD: standard deviation 


\section{Discussion}

The changes caused by SCA in the peripheral retina and macula have been known for a long time. Early histopathological changes have shown that patients with SCA develop thinning and atrophy in the inner retina, inner nuclear, and ganglion cell layers. ${ }^{9-11}$ Retinal thinning is chronic and has a progressive course in patients with SCA. ${ }^{12}$ Thinning in the temporal macula has been reported to occur in early childhood. ${ }^{13}$ The researchers reported that macular thinning was associated with perifoveal flow defect and peripheral neovascularization. ${ }^{14,15}$ Observing disorders such as microaneurysm in macula and an increase in the foveal avascular zone, especially in the temporal region, has been associated with terminal vessels in this region being more sensitive to occlusion. ${ }^{16}$ The development of proliferative retinopathy is associated with the presence of temporal thinning in these patients, but it should be noted that even two-thirds of these patients may be asymptomatic. ${ }^{11}$

While homozygous hemoglobin $\mathrm{S}$ disease (Hb SS) is associated with more severe clinical symptoms in patients with SCA, $\mathrm{Hb}$ SC disease has been reported to be associated with more severe and earlier retinal disease.,17 Lim et al. ${ }^{18}$ stated that patients with the $\mathrm{Hb}$ SC genotype were more prone to developing proliferative retinopathy, but macular thinning was observed more in $\mathrm{Hb}$ SS patients. More vaso-occlusive events were observed occuring in $\mathrm{Hb}$ SS patients; however, it was noted that proliferative retinopathy was paradoxically less developed in these patients. However, Cai et al. ${ }^{12}$ did not detect any differences between $\mathrm{Hb}$ $\mathrm{SS}$ and $\mathrm{Hb} \mathrm{SC}$ in terms of macular thinning. In our study, all of our patients were $\mathrm{Hb}$ SS, and $\mathrm{Hb} \mathrm{SC}$ was not detected in our patient group.

Indirect ophthalmoscopy is usually the first line for the identification of signs of retinopathy but is dependent on operator experience and deep knowledge of the disease. Retinopathy can be detected in $10 \%$ of cases with standard fundus examination performed with a 90
D lens after dilatation. On the other hand, more sensitive methods such as wide-field fluorescein angiography (FA), SD-OCT, and optical coherence tomography angiography (OCTA) enable the early detection of sickle cell retinopathy. These imaging methods guide the formation of screening and treatment algorithms as well as a better understanding of the pathogenesis of the disease.

Minvielle et al. $^{19}$ showed microvascular abnormalities in the perifoveal and macular areas by FA in half of the patients without visual impairment and stated that this could be explained by capillary filling defects in the intermediate and deep plexuses. Another study reported that macular thinning areas on SD-OCT were associated with the degree of peripheral ischemia on wide-field FA. ${ }^{13}$ However, many studies stated that there could be no findings on FA. ${ }^{9-11}$ In the present study, none of the patients had retinal pathology that would require FA.

OCT Angiography is a new imaging technique that enables retinal vascular pathologies to be examined in more detail. The vascular loss was found to be the same in both genotypes as a result of evaluations by OCTA in patients with SCA. ${ }^{20}$ However, in patients with proliferative retinopathy, vascular defects were observed to be higher in the deep plexus in the parafoveal, temporal, and nasal regions. Studies with OCTA demonstrated that vascular defects in retinal areas were associated with thinning in these areas. Han et al. ${ }^{9}$ reported that retinal thickness measurements were correlated with foveal, parafoveal, superior and temporal vascular density, while visual acuity was correlated with foveal avascular zone, parafoveal vascular density in the superficial and deep plexuses. In the present study, we did not have the opportunity to perform OCTA to our patients. However, studies have revealed pathologies correlated with SD-OCT in the perfusion defect areas detected by OCTA. ${ }^{21,22}$ Grego et al..$^{22}$ did not detect additional flow gap areas other than macular thinning identified by SD-OCT in OCTA, and stated that the SD-OCT findings 
supported the OCTA findings in patients with SCA.

SD-OCT is a non-invasive, reproducible, and easily applicable imaging method. This method allows us to have an idea about possible macular, retinal, and RNFL changes that may occur as a result of ischemia and neovascularization in the retinal layers. Han et al. ${ }^{9}$ showed that approximately $50 \%$ of eyes with SCA developed focal macular thinning without clinically significant maculopathy on SD-OCT. Besides subclinical foveal thinning and splaying, thinning in the outer retinal layer in the central, foveal temporal and parafoveal regions have been reported in patients without significant focal thinning. ${ }^{21}$ Martin et al. ${ }^{23}$ determined that $64 \%$ of SCA patients in early childhood had atrophy in the paramacular temporal region. The researchers linked this to chronic perfusion disorder in relation to the severity of the disease and stated that it could be used as a marker in other possible systemic complications. The choroid is the tissue with the highest rate of blood flow per volume in the body. The choroid, which has a rich vascular network, consists of melanocytes, nerves, extracellular fluid, and connective tissue. With the development of imaging methods, the choroid and retinal layers could be examined in more detail, and it became possible to gain information about retinal and choroidal changes in systemic and ocular diseases. ${ }^{15}$ EDI-OCT is an imaging method that enables measuring choroidal thickness thanks to the choroid sections it provides. Although these measurements are not precise, it allows us to have information about blood flow to choroidal tissue. $^{24}$

In the present study, choroidal thickness was evaluated in detail in 7 different quadrants. Choroidal thinning was observed in 6 quadrants in SCA patients compared to the healthy group. Choroidal thinning in these patients can be explained by slower flow and sickling of red blood cells in the choriocapillaris. In addition, anemia observed in these patients results in choroidal blood flow changes by leading to systemic vasoconstriction and cardiac output changes and may cause a decrease in choroidal thickness.

Grego et al. ${ }^{22}$ reported that complications such as retinopathy and maculopathy are associated with hemolysis indices such as low hemoglobin and hematocrit rates, high reticulocyte percentage, and high total bilirubin levels. Vatansever et al. ${ }^{25}$ stated that there was no difference in foveal flattening and temporal thinning between with and without a history of sequestration crisis in patients with SCA. In our study, no relationship was found between the number of crisis and macular thickness. However, we found that choroidal thickness and RNFL values were not related to the number of crisis. We think that this is because the main factor causing changes in the choroid and RNFL are parameters such as blood flow, anemia and hypoxia rather than the number of crisis.

RNFL is considered as a marker in the evaluation of retinal ganglion cell (RGC) functions. RGC plays an important role in the transmission of the visible image to the brain. ${ }^{26}$ Vaso-occlusive changes leading to macular thinning in patients with SCA are likely to cause changes in peripapillary RNFL. It has been reported that peripapillary RNFL thinning may occur in ischemic retinopathy types such as diabetes and artery/vein occlusions..$^{27,28}$ An adult study reported that thinning was observed in the nasal and inferior quadrants in the case of Fe deficiency. ${ }^{29}$ None of our patients had Fe deficiency, so this factor was not a confounding factor in this study. The degree of peripapillary RNFL thinning may related to the severity of macular thinning. Chow et al. ${ }^{30}$ observed a significant thinning in the peripapillary RNFL of SCA patients with focal macular thinning compared to those without focal macular thinning. RNFL thinning was also observed in patients without focal macular thinning, but this difference was much less compared to those with focal macular thinning. On the other hand, Brasileiro et al. ${ }^{10}$ did not 
observe RNFL thinning in adult SCA patients without retinopathy compared to the control group. These changes in RNFL values of SCA patients pose a new problem. When performing RNFL analysis, these patients require different peripapillary RNFL thickness thresholds for glaucoma evaluations. Clinicians should be more careful when diagnosing glaucoma in these patients.

In the present study, SCA patients had significant RNFL thinning in the temporal, inferotemporal, and nasal quadrants compared to the healthy group. We think that these changes in peripapillary RNFL are associated with thinning and atrophy of macular inner retinal layers caused by perfusion defects. It should be kept in mind that RNFL losses in these patients may also be associated with hypomyelination, which occurs after nerve myelination and neurotransmitter synthesis defect.

This study had some limitations. Firstly, the number of patients is not enough, there is a need for a larger series of cases in this regard. The fact that cross-sectional examination was performed in these patients and that they were not ophthalmologically followed for a long time makes it difficult to have an idea about the progression of the disease. Long-term follow-up is needed to determine the relationship between the onset of disease symptoms and hematological parameters. A study of SCA children reported that proliferative disease developed in $43 \%$ of $\mathrm{Hb}$ SC patients and $14 \%$ of $\mathrm{Hb}$ SS patients in the 20 years. ${ }^{2}$ Early diagnosis and treatment is the basis for preventing disease progression to the proliferative stage. The American Academy of Pediatrics recommends performing retinopathy screening in children for $\mathrm{Hb}$ SS and $\mathrm{Hb}$ SC by dilated fundoscopic examination, starting from 10 years of age. ${ }^{31}$ Secondly, none of our patients underwent FA. However, it should be noted that FA is recommended only if there is a suspicious lesion in the fundus. ${ }^{32}$ None of our patients had an indication for the FA application.

In the present study, thinning was observed in choroidal thickness and RNFL measurements, but there was no change in macular thickness in the evaluations of SCA patients by SD-OCT. The findings suggest that SD-OCT may be useful for the diagnosis and screening of retinopathy. Considering its widespread use and ease of image acquisition in pediatric populations, SD-OCT can be used more frequently in the screening examination of patients. Increasing awareness of the subclinical disease in this way will provide an opportunity for early identification of retinopathy and reducing possible visual loss.

\section{Acknowledgement}

We appreciate the University Medical School of Dicle for providing access to their patient data.

\section{Author contribution}

The authors confirm contribution to the paper as follows: study conception and design: $\mathrm{KY}$, HÖ; data collection: KY, HÖ, HU, KÖ; analysis and interpretation of results: KY, MS, EDY; draft manuscript preparation: KY, MS, HÖ. All authors reviewed the results and approved the final version of the manuscript.

\section{Ethical approval}

The study was conducted based on the rules of Declaration of Helsinki and approved by the Institutional Ethics Committee of Dicle University Faculty of Medicine. (23.06.2017report number:24).

\section{Source of funding}

No funding was received from any source for this research.

\section{Conflict of interest}

The authors have no conflict of interests to declare. All the authors contributed to the study. 


\section{REFERENCES}

1. Ünal S. Orak hücreli anemi tedavi ve izlem. Türk Hematoloji Derneği. HematoLog 2014; 4: 79-93.

2. Downes SM, Hambleton IR, Chuang EL, Lois N, Serjeant GR, Bird AC. Incidence and natural history of proliferative sickle cell retinopathy: observations from a cohort study. Ophthalmology 2005; 112: 1869-1875.

3. Fadugbagbe $\mathrm{AO}$, Gurgel $\mathrm{RQ}$, Mendonca $\mathrm{CQ}$, Cipolotti R, dos Santos AM, Cuevas LE. Ocular manifestations of sickle cell disease. Ann Trop Paediatr 2010; 30: 19-26.

4. Elagouz M, Jyothi S, Gupta B, Sivaprasad S. Sickle cell disease and the eye: old and new concepts. Surv Ophthalmol 2010; 55: 359-377.

5. Moriarty BJ, Acheson RW, Condon PI, Serjeant GR. Patterns of visual loss in untreated sickle cell retinopathy. Eye (Lond) 1988; 2(Pt 3): 330-335.

6. Murthy RK, Grover S, Chalam KV. Temporal macular thinning on spectral-domain optical coherence tomography in proliferative sickle cell retinopathy. Arch Ophthalmol 2011; 129: 247-249.

7. Chow CC, Genead MA, Anastasakis A, Chau FY, Fishman GA, Lim JI. Structural and functional correlation in sickle cell retinopathy using spectral domain optical coherence tomography and scanning laser ophthalmoscope microperimetry. Am J Ophthalmol 2011; 152: 704-711.

8. Goldberg MF, Galinos S, Lee CB, Stevens T, Woolf MB. Editorial: macular ischemia and infarction in sickling. Invest Ophthalmol 1973; 12: 633-635.

9. Han IC, Tadarati M, Pacheco KD, Scott AW. Evaluation of macular vascular abnormalities identified by optical coherence tomography angiography in sickle cell disease. Am J Ophthalmol 2017; 177: 90-99.

10. Brasileiro F, Martins TT, Campos SB, et al. Macular and peripapillary spectral domain optical coherence tomography changes in sickle cell retinopathy. Retina 2015; 35: 257-263.

11. Hoang QV, Chau FY, Shahidi M, Lim JI. Central macular splaying and outer retinal thinning in asymptomatic sickle cell patients by spectral-domain optical coherence tomography. Am J Ophthalmol 2011; 151: 990-994.e1.

12. Cai CX, Han IC, Tian J, Linz MO, Scott AW. Progressive retinal thinning in sickle cell retinopathy. Ophthalmol Retina 2018; 2: 1241-1248.e2.

13. Ghasemi Falavarjani K, Scott AW, Wang K, et al. Correlation of multimodal imaging in sickle cell retinopathy. Retina 2016; 36(Suppl 1): S111-S117.
14. Do BK, Rodger DC. Sickle cell disease and the eye Curr Opin Ophthalmol 2017; 28: 623-628.

15. Hood MP, Diaz RI, Sigler EJ, Calzada JI. Temporal macular atrophy as a predictor of neovascularization in sickle cell retinopathy. Ophthalmic Surg Lasers Imaging Retina 2016; 47: 27-34.

16. Stevens TS, Busse B, Lee CB, Woolf MB, Galinos SO, Goldberg MF. Sickling hemoglobinopathies; macular and perimacular vascular abnormalities. Arch Ophthalmol 1974; 92: 455-463.

17. Fox PD, Dunn DT, Morris JS, Serjeant GR. Risk factors for proliferative sickle retinopathy. $\mathrm{Br} \mathrm{J}$ Ophthalmol 1990; 74: 172-176.

18. Lim WS, Magan T, Mahroo OA, Hysi PG, Helou J, Mohamed MD. Retinal thickness measurements in sickle cell patients with $\mathrm{HbSS}$ and HbSC genotype. Can J Ophthalmol 2018; 53: 420-424.

19. Minvielle W, Caillaux V, Cohen SY, et al. Macular microangiopathy in sickle cell disease using optical coherence tomography angiography. Am J Ophthalmol 2016; 164: 137-144.e1.

20. Mathew R, Bafiq R, Ramu J, et al. Spectral domain optical coherence tomography in patients with sickle cell disease. Br J Ophthalmol 2015; 99: 967-972.

21. Han IC, Tadarati M, Scott AW. Macular vascular abnormalities identified by optical coherence tomographic angiography in patients with sickle cell disease. JAMA Ophthalmol 2015; 133: 1337-1340.

22. Grego L, Pignatto S, Alfier F, et al. Optical coherence tomography (OCT) and OCT angiography allow early identification of sickle cell maculopathy in children and correlate it with systemic risk factors. Graefes Arch Clin Exp Ophthalmol 2020; 258: 25512561.

23. Martin GC, Albuisson E, Brousse V, de Montalembert M, Bremond-Gignac D, Robert MP. Paramacular temporal atrophy in sickle cell disease occurs early in childhood. Br J Ophthalmol 2019; 103: 906-910.

24. Spaide RF, Koizumi H, Pozzoni MC. Enhanced depth imaging spectral-domain optical coherence tomography. Am J Ophthalmol 2008; 146: 496-500.

25. Vatansever E, Vatansever M, Dinç E, Temel GÖ, Ünal S. Evaluation of ocular complications by using optical coherence tomography in children with sickle cell disease eye findings in children with sickle cell disease. J Pediatr Hematol Oncol 2020; 42: 92-99.

26. Mead B, Tomarev S. Evaluating retinal ganglion cell loss and dysfunction. Exp Eye Res 2016; 151: 96-106. 
27. Lonneville YH, Ozdek SC, Onol M, Yetkin I, Gürelik G, Hasanreisoğlu B.The effect of blood glucose regulation on retinal nerve fiber layer thickness in diabetic patients. Ophthalmologica 2003; 217: 347350 .

28. Leung CK, Tham CC, Mohammed S, et al. In vivo measurements of macular and nerve fibre layer thickness in retinal arterial occlusion. Eye (Lond) 2007; 21: 1464-1468.

29. Akdogan E, Turkyilmaz K, Ayaz T, Tufekci D. Peripapillary retinal nerve fibre layer thickness in women with iron deficiency anaemia. J Int Med Res 2015; 43: 104-109.
30. Chow CC, Shah RJ, Lim JI, Chau FY, Hallak JA, Vajaranant TS.Peripapillary retinal nerve fiber layer thickness in sickle-cell hemoglobinopathies using spectral-domain optical coherence tomography. Am J Ophthalmol 2013; 155: 456-464.e2.

31. Section on Hematology/Oncology Committee on Genetics; American Academy of Pediatrics. Health supervision for children with sickle cell disease. Pediatrics 2002; 109: 526-535.

32. Habibi A, Arlet JB, Stankovic K, et al. French guidelines for the management of adult sickle cell disease: 2015 update. Rev Med Interne 2015; 36(5 Suppl 1): 5S3-5S84. 